\title{
In Deep UV Quantitative Analysis of Multi-Element Low Alloy Steel by Laser-Induced Breakdown Spectroscopy
}

\author{
Yong Xin, Lanxiang Sun", Zhibo Cong, Lifeng Qi, Yang Li, Zhijia Yang
}

Lab. of Networked Control Systems, Shenyang Institute of Automation, Chinese Academy of Sciences, Shenyang 110016, China. Email: xinyong@sia.cn, *sunlanxiang@sia.cn

Received August 2013

\begin{abstract}
The multi-element components of low alloy steel were quantified by using laser-induced breakdown spectroscopy (LIBS) in deep UV. The Nd:YAG pulsed laser was used to produce plasma. The spectrum was simultaneously obtained by deep UV spectrometer. This paper studied the influence of experiment parameters on LIBS spectral intensity, such as delay, energy of laser, and the distance between the focusing lens and the surface of the sample. With the optimal experiment parameters, the characteristic lines of $\mathrm{C}, \mathrm{Ni}, \mathrm{Si}, \mathrm{Cr}$ and $\mathrm{Cu}$ contained in low alloy steel were selected for quantitative analysis and the calibration curves of these elements were obtained. The linear correlation coefficient was good. Using the calibration curves to quantitative analysis for the sample 05-d, and the relative error of analytical results is less than $10 \%$ for most elements.
\end{abstract}

Keywords: Laser-Induced Breakdown Spectroscopy; Plasma; Quantitative Analysis; Deep UV

\section{Introduction}

Laser-Induced Breakdown Spectroscopy (LIBS) is a recently developed qualitative and quantitative technology that is based on the interaction of laser and material. Due to its simultaneous and fast analysis for multi-elements, no need for preparing sample and simultaneous determination of solid, liquid and gas, LIBS attracted attentions of scholars at home and abroad [1-8], and had significant application value. NOLL team of Germany ILT [3] adopted LIBS to analyze the component of solid high alloyed steel and made quantitative analysis for nine elements including $\mathrm{Ni}, \mathrm{Cr}, \mathrm{Cu}, \mathrm{Mo}, \mathrm{Si}, \mathrm{Ti}, \mathrm{Mn}, \mathrm{Al}$, and C. Capitelli et al. [4] analyzed the content of $\mathrm{Cr}, \mathrm{Cu}, \mathrm{Fe}, \mathrm{Mn}$ and $\mathrm{Ni}$ etc., but the result was not as good as that of ICP-OES. Lu Jidong [5] form Huazhong University of Science and Technology studied the carbon content of ashes by LIBS technology. In addition, Sun lanxiang et al. $[7,8]$ from Shenyang Institute of Automation Chinese Academy of Science also made a series of researches on steel alloy by LIBS.

In the steel industry, it is very important for real-time online analysis of $\mathrm{C}, \mathrm{Si}$, Cr, etc., element of the component content. For the $\mathrm{C}$ element, the characteristic line $193.03 \mathrm{~nm}$ has no strong influence on other lines. So we choose a deep UV, high resolution of spectrometer (175 $\mathrm{nm}-250 \mathrm{~nm}$ ) to collect the signal of plasma spectrum.

*Corresponding author.
Since LIBS experiment is susceptible to the influence of laser energy, wavelength, surrounding environment and delay, etc., the fluctuation of experiment data is large, and the accuracy is not high. Therefore, there are many problems that need to be solved in quantitative analysis. In this paper, we first systematically studied the influence of experiment parameters on LIBS spectral intensity, then in the optimum parameters. The $\mathrm{C}, \mathrm{Ni}, \mathrm{Si}, \mathrm{Cr}$ and $\mathrm{Cu}$ in low-alloy steel were quantitatively analyzed.

\section{Experimental}

\subsection{Experimental System}

As shown in Figure 1, the experimental system is selfbuilt. The laser is Nd:YAG pulse laser ( CFR200, Big Sky Company) with a wavelength of $1064 \mathrm{~nm}$, pulse width of $10 \mathrm{~ns}$, and the largest pulse energy of $200 \mathrm{~mJ}$. The deep UV fiber optic spectrometer (AvaSpec-ULS2048-USB2) has a response wavelength of $175-250 \mathrm{~nm}$, optical resolution of $0.05-0.08 \mathrm{~nm}$ (FWHM) and shortest integration time of $1 \mathrm{~ms}$. The signal delay controller is self-developed trigger module suitable to the LIBS system.

The experimental process: the laser of $1064 \mathrm{~nm}$ was reduced by laser attenuator to appropriate energy and then was focused onto sample by plano-convex lens with a focal length of $150 \mathrm{~mm}$ to produce plasma. The plasma 
spectrum was focused onto fiber optic spectrometer by collection system, and the spectrum was finally obtained. In this experiment, the energy is monitored real-time by energy meter and the delay between laser and spectrometer is controlled by signal delay controller.

\subsection{Analysis Sample}

The analysis sample is low alloy steel standards, which is made in JFE Techno-Research Corporation of Japan. The composition of low alloy steel is shown in Table 1.

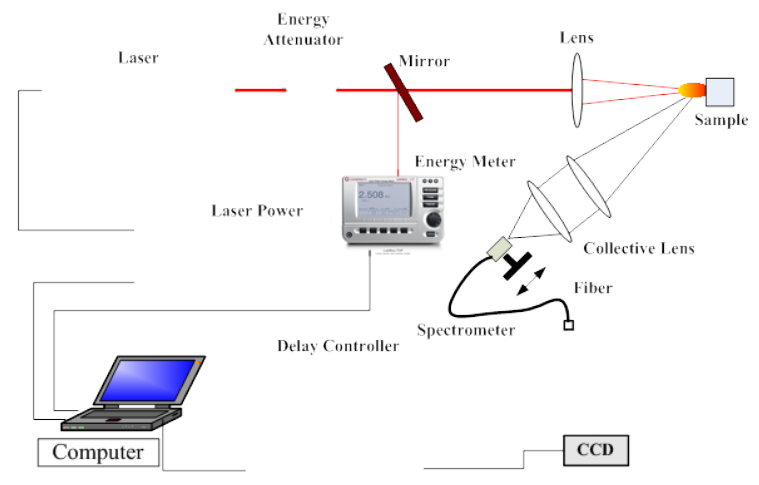

Figure 1. The schematic diagram of the LIBS experiment setup.

\section{Result and Discussion}

\subsection{The Influence of Experimental Parameters on the Spectrum}

The early evolution of laser-induced plasma, there is strong continuous background radiation. The characteristic lines are submerged in a continuous background radiation. Due to the spectral intensity of the continuous background decay rate faster than the characteristic lines, the signal to noise ratio of lines will reach the maximum at a time. So choose a suitable delay is crucial for LIBS spectroscopy.

The distance between the focusing lens and the surface of the sample will determine the size of focus spot, and will affect the power density of the laser, which is focused on the sample surface, so it will have an important effect on plasma spectroscopy.

As Figures 2 and $\mathbf{3}$ show, the best experiment condition: delay is 0.83 us, the distance between the focusing lens and the surface of the sample is $145 \mathrm{~mm}$ (focal length is $150 \mathrm{~mm}$ ), pules energy is $140 \mathrm{~mJ}$.

\subsection{Quantitative Analysis}

During the experiment, before testing the sample, the sample is conducted with pre-treatment (shot by laser for 30 times) to remove the oxide layer and impurity on the sample surface. 300 data were collected under each experiment condition.

Table 1. Composition of Samples.

\begin{tabular}{|c|c|c|c|c|c|c|c|c|c|c|c|}
\hline \multirow{2}{*}{$\begin{array}{c}\text { Sample } \\
\text { No. }\end{array}$} & \multicolumn{11}{|c|}{ Concentration（\%） } \\
\hline & $\mathrm{C}$ & Si & $\mathrm{Ni}$ & $\mathrm{Cr}$ & $\mathrm{Cu}$ & $\mathrm{Mn}$ & $\mathrm{P}$ & $\mathrm{S}$ & Mo & $\mathrm{V}$ & $\mathrm{Ti}$ \\
\hline 01-g & 0.0009 & $<0.01$ & 0.01 & 0.01 & 0.01 & 0.01 & 0.01 & 0.002 & 0.001 & 0.001 & 0.001 \\
\hline 02-d & 0.1 & 0.6 & 0.05 & 4.02 & 0.07 & 0.15 & - & 0.0032 & 0.5 & 0.4 & 0.022 \\
\hline 03-d & 0.149 & 0.4 & 0.1 & 3.22 & 0.69 & 0.75 & - & 0.006 & 0.4 & 0.027 & 0.1 \\
\hline 04-d & 0.21 & 0.06 & 0.5 & 2.51 & 0.11 & 2.0 & 0.008 & 0.016 & 0.3 & - & 0.3 \\
\hline 05-d & 0.26 & 0.25 & 1.05 & 2.02 & 0.4 & 1.6 & 0.013 & 0.0017 & 0.092 & 0.3 & 0.014 \\
\hline 06-d & 0.34 & 0.34 & 1.55 & 1.49 & 0.49 & 1.29 & 0.048 & 0.0013 & 0.2 & 0.058 & 0.054 \\
\hline 07-d & 0.5 & 0.3 & 2.02 & 1.02 & 0.2 & 1.02 & 0.038 & 0.026 & 0.6 & 0.11 & 0.2 \\
\hline 08-d & 0.64 & 0.15 & 2.53 & 0.53 & 0.3 & 0.51 & 0.028 & 0.02 & 1.02 & 0.16 & 0.16 \\
\hline 09-d & 0.8 & 0.2 & 3.26 & 0.12 & 0.17 & 0.31 & 0.018 & 0.0029 & 0.82 & 0.2 & - \\
\hline $10-d$ & 0.99 & 0.11 & 4.06 & 0.05 & 0.05 & 0.1 & 0.003 & 0.009 & 0.059 & 0.49 & - \\
\hline
\end{tabular}

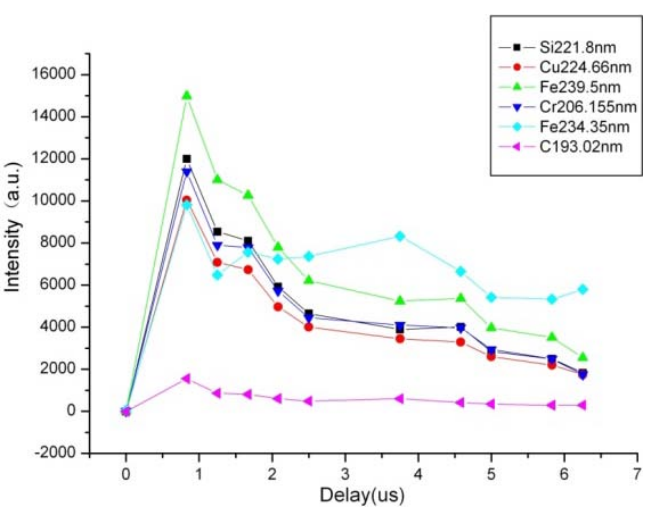

Figure 2. The delay versus the intensity of spectrum.

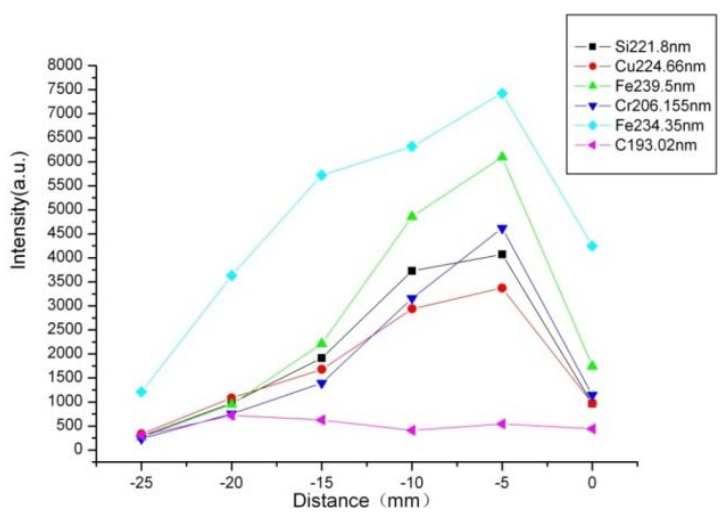

Figure 3. The distance versus the intensity of spectrum. 
The characteristic lines of $\mathrm{C}, \mathrm{Ni}, \mathrm{Si}, \mathrm{Cr}$ and $\mathrm{Cu}$ contained in low alloy steel were selected for research. Using the linear calibration method to calibrate the five elements.

Figure 4 is the calibration curve of $\mathrm{C}, \mathrm{Ni}, \mathrm{Si}, \mathrm{Cr}$ and $\mathrm{Cu}, \mathrm{x}$-axis is the concentrations of the analysis of elemental, $y$-axis is intensity of the analysis of elemental.

As can be seen from the Figure 4, the linear correlation coefficient of $\mathrm{C}, \mathrm{Ni}, \mathrm{Cr}$ and $\mathrm{Cu}$ is good, and $\mathrm{Si}$ is slightly lower. The calibration curve indicates that ele-
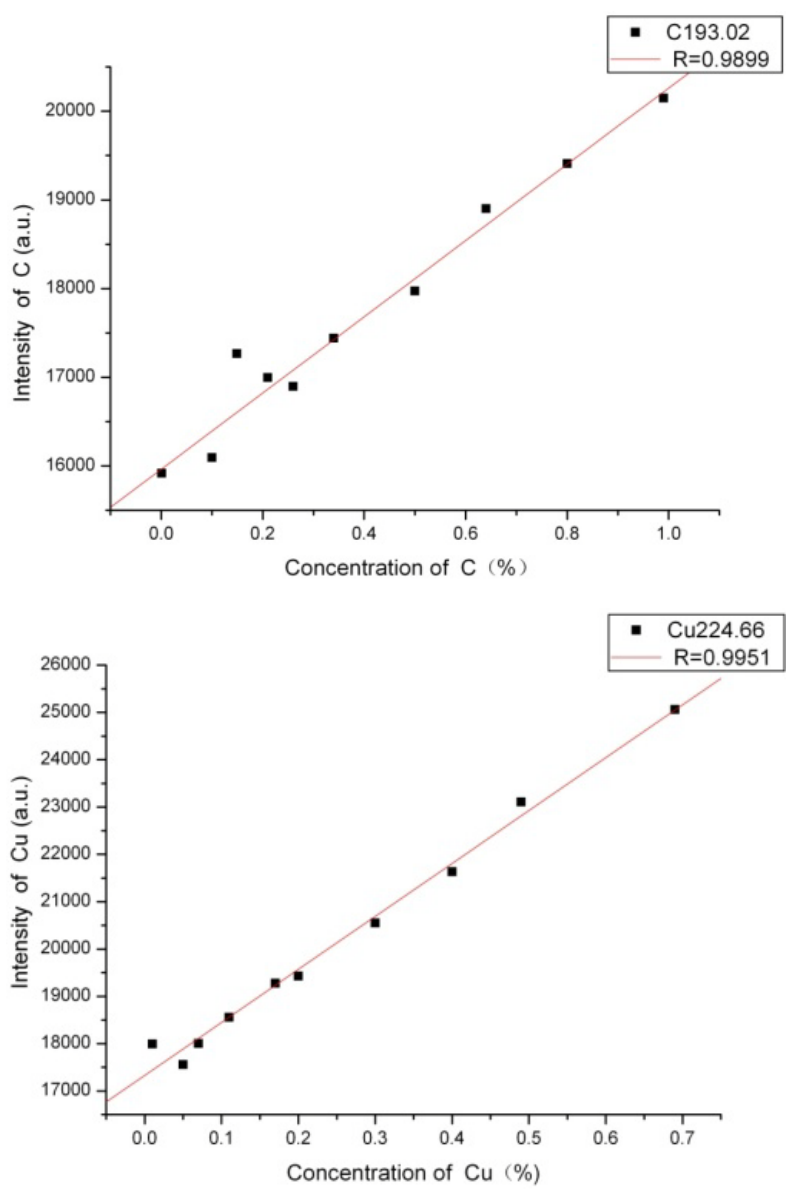

ment concentration and spectral intensity have a good linear relationship.

Quantitative analysis sample 05-d using the calibration curves, the analytical results are shown in Table 2.

It can be seen from Table 2 that the relative error of analytical results is less than $10 \%$, in addition to the element $\mathrm{Si}$, this may be due to that the distribution of $\mathrm{Si}$ element in sample is not homogeneous. The results show that the accuracy of analysis results is relatively high.
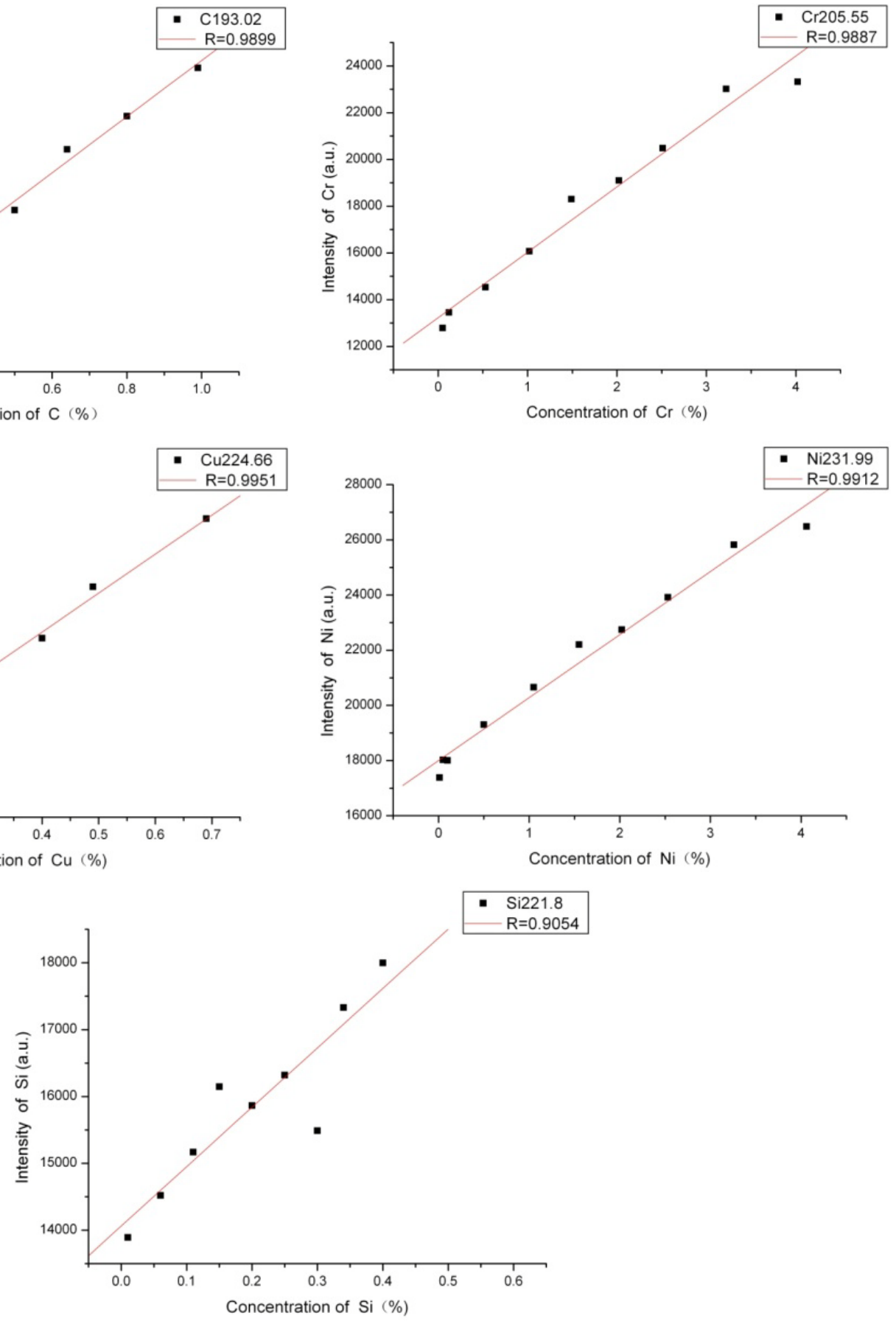

Figure 4. The calibration curve of $\mathrm{C}, \mathrm{Ni}, \mathrm{Si}, \mathrm{Cr}$ and $\mathrm{Cu}$. 
Table 2. Quantitative results of low alloy steel 05-d.

\begin{tabular}{cccccc}
\hline & $\mathrm{C}$ & $\mathrm{Cr}$ & $\mathrm{Cu}$ & $\mathrm{Ni}$ & $\mathrm{Si}$ \\
\hline Real value (\%) & 0.26 & 2.02 & 0.4 & 1.05 & 0.25 \\
Analytical value (\%) & 0.208 & 2.097 & 0.385 & 1.164 & 0.254 \\
Relative error (\%) & -1.67 & 3.82 & -3.88 & 10.82 & 19.99 \\
\hline
\end{tabular}

\section{Conclusions}

This paper first studied the influence of experiment parameters, such as delay, energy of laser, and the distance between the focusing lens and the surface of the sample on LIBS spectral intensity. Then in the best experiment conditions, the characteristic lines of $\mathrm{C}, \mathrm{Ni}, \mathrm{Si}, \mathrm{Cr}$ and $\mathrm{Cu}$ contained in low alloy steel were selected for simultaneous quantitative analysis. The experimental results show that the element concentration and spectral intensity have a better linear relationship. The relative error of analytical results is less than $10 \%$ for most elements in low alloy steel.

Due to LIBS technology having fast analysis for multielements, there is no need for preparing sample and so on. It is ideally suited for steel industrial online analysis. In steel industry, deep UV quantitative analysis of sample is very effective.

\section{Acknowledgements}

This work has been supported by the Equipment Development Programs of the Chinese Academy of Sciences (Grant No. YZ201247), the National High-Tech Research and Development Program of China (863 Program) (Grant No. 2012AA040608) and the National Natural Science Fund (Grant No. 61004131).

\section{REFERENCES}

[1] D. A. Cremers and L. J. Radziemski, "Handbook of Laser-Induced Breakdown Spectroscopy: Methods and Ap- plications," Wiley Press, 2006. http://dx.doi.org/10.1002/0470093013

[2] A. W. Miziolek, V. Palleschi, I. Schechter, et al., "LaseInduced Breakdown Spectroscopy Fundamentals and Applications,” Cambridge University Press, 2006. http://dx.doi.org/10.1017/CBO9780511541261

[3] J. Vrenegor, R. Noll and V. Sturm, "Investigation of Matrix Effects in Laser-Induced Breakdown Spectroscopy Plasmas of High-Alloy Steel for Matrix and Minor Elements," Spectrochim Acta B, Vol. 60, No. 7-8, 2005, pp. 1083-1091. http://dx.doi.org/10.1016/j.sab.2005.05.027

[4] F. Capitelli, F. Colao, M. R. Provenzano, et al., "Determination of Heavy Metals in Soils by Laser Induced Breakdown Spectroscopy," Geoderma, Vol. 106, No. 1, 2002, pp. 45-62.

http://dx.doi.org/10.1016/S0016-7061(01)00115-X

[5] G. Wu, J. D. Lu and L. Y. Yu, "The Determination of Carbon Content in Ashes by Laser-Induced Breakdown Spectroscopy,” Journal of Engineering for Thermal Energy and Power, Vol. 20, No. 4, 2005, pp. 365-368.

[6] L. M. Cabalin and J. J. Laserna, "Experimental Determination of Laser Induced Breakdown Thresholds of Metals under Nanosecond Q-Switched Laser Operation,” Spectrochim Acta B, Vol. 53, No. 5, 1998, pp. 723-730. http://dx.doi.org/10.1016/S0584-8547(98)00107-4

[7] L. X. Sun and H. B. Yu, "Simultaneous Quantitative Analysis of Multielement in Al Alloy Samples by Laser-Induced Breakdown Spectroscopy,” Spectroscopy and Spectral Analysis, Vol. 29, No. 12, 2009, pp. 3375-3378.

[8] L. X. Sun, H. B. Yu and Y. Xin, “On-Line Monitoring of Molten Steel Compositions by Laser-Induced Breakdown Spectroscopy,” Chinese Journal of Lasers, Vol. 38, No. 9, 2011, Article ID: 091500. http://dx.doi.org/10.3788/CJL201138.0915002 